\title{
NEGOCIAÇÕES COLETIVAS NO BRASIL: BREVE ANÁLISE DO PERÍODO 2000-2006 E SUAS TENDÊNCIAS
}

\author{
Brazilian collective bargaing: brief analysis of the \\ 2000-2006 period and its trends
}

Envio14.10.08/ Aceite 17.03.09

\section{Wilson Aparecido Costa de Amorim ${ }^{1}$}

\section{Resumo}

O objetivo deste artigo é analisar as negociações coletivas no Brasil, no período 2000-2006, e os desafios futuros em termos de tendências. Os dados apontaram que as mudanças expressivas nas estruturas, processos e conteúdos das negociações coletivas da década de 1990 consolidaram um novo quadro na atual década. Nos últimos anos, a agenda da negociação coletiva brasileira mostrou-se ampliada por novas temáticas e processos em nível nacional e internacional.

Palavras-chave: Bubalinocultura; Inovação; Parcerias Estratégicas.

\begin{abstract}
This paper proposes the analysis of Brazilian collective bargaining, its challenges and trends during the period 2000-2006. The paper points out that the impressive changes in collective bargaining structures, processes and contents built up new conditions in the nineties. Brazilian collective bargaining from 2000 to 2006 showed new contents and processes at national and international levels.
\end{abstract}

Keywords: Collective Bargaining; Labor Relations.

\footnotetext{
${ }_{1}^{1}$ Professor e pesquisador do PROGEP-FIA/USP. E-mail: wilsonamorim@bighost.com.br
} 


\section{Introdução ${ }^{2}$}

Após quase 30 anos do ressurgimento sindical brasileiro nas primeiras greves do $A B C$ paulista, as negociações coletivas, suas práticas e resultados passaram por mudanças expressivas, que, por sua vez, acompanharam de perto as transformações que a própria economia e sociedade brasileira também experimentaram. Especialmente após 1990, essas mudanças foram ainda mais fortes, com a abertura do mercado interno e a queda da inflação após o Plano Real. Dessa forma, o objetivo deste trabalho é analisar o processo de negociações coletivas no Brasil no período 2000-2006 e os desafios que estes anos desenharam para o futuro em termos de tendências.

Para isso, além desta introdução, o capítulo conta com as seguintes seções: referencial teórico para análise das negociações; breve análise sobre as mudanças da década de 1990; análise geral do período 2000-2006; tendências para as negociações coletivas; conclusão.

\section{Referencial teórico para análise das negociações}

O conceito de relações do trabalho é alvo de grande discussão entre os teóricos dessa área. John T. Dunlop participou ativamente dos debates sobre o assunto, desde o final da década de 1950, e é uma de suas principais referências. Para esse autor, as relações do trabalho podem ser compreendidas como um sistema em que existem três elementos-chave: atores (trabalhadores, empresas e Estado), ambiente e ideologia. Os atores interagem em um ambiente marcado por forças econômicas, sociais e tecnológicas, definindo suas regras de funcionamento. A coesão desse sistema é garantida pelo conjunto de idéias e crenças partilhado pelos seus atores, ou seja, sua ideologia. Esse sistema faz parte de outro ainda maior, o sistema social, e estaria no mesmo plano do sistema econômico (DUNLOP, 1972, p. 549).

Ao definir as relações de trabalho como sistema, Dunlop recebeu críticas do campo econômico mais conservador, pois seu esquema explicativo concederia excessiva importância aos sindicatos, que seriam uma "imperfeição de mercado". Outras críticas originavam-se no outro extremo do espectro ideológico, já que a concepção das relações de trabalho como um sistema não consideraria plenamente o antagonismo existente entre as classes sociais envolvidas na produção, bem como as contradições aí existentes ${ }^{3}$. De fato, por definição, no campo das relações do trabalho, existem interesses antagônicos de classe e não os considerar cria o risco de conceber o sistema como um mecanismo social da busca permanente de uma estabilidade e de negação desse conflito (NOGUEIRA, 2002, p. 116).

Todavia, mesmo com essas críticas, o conceito de Dunlop oferece interessantes elementos para análise das relações do trabalho, tais como o seu contexto (indicado pelas forças ambientais externas principalmente), seus atores (as partes que negociam), suas regras de funcionamento e as mudanças dessas regras (a forma como a negociação acontece). Por meio desses elementos, torna-se viável, por exemplo, estudar a evolução do sistema de um mesmo país - intenção deste trabalho -, de um setor econômico, ou mesmo estabelecer comparações internacionais, razão pela qual ele é adotado aqui como uma referência.

\footnotetext{
${ }^{2}$ Este trabalho tem por base um capítulo de livro, no prelo, organizado pela CEPAL e a OIT no Brasil e também contou com o apoio do PROGEP-FIA/USP.
} 
Dessa forma, a partir da concepção de Dunlop, a análise das negociações coletivas brasileiras será feita com base em quatro elementos como descrito no Quadro 1.

\begin{tabular}{c|c|c|l|c}
\hline Ano & $\begin{array}{c}\text { PIB - } \\
\text { Crescimento } \\
\text { (anual) (\%) (1) }\end{array}$ & $\begin{array}{c}\text { Desemprego } \\
\text { Total -RMSP } \\
(\mathbf{2})\end{array}$ & $\begin{array}{c}\text { Inflação (tendência } \\
\text { ao longo do ano) } \\
\mathbf{( 3 )}\end{array}$ & $\begin{array}{c}\text { Reajustes } \\
\text { salariais iguais } \\
\text { ou superiores ao } \\
\text { INPC/IBGE (4) } \\
\text { (\%) }\end{array}$ \\
\hline 1990 & $-4,4$ & 10,3 & em elevação & Nd \\
\hline 1991 & 1,0 & 11,7 & em elevação & Nd \\
\hline 1992 & $-0,5$ & 15,2 & em elevação & Nd \\
\hline 1993 & 4,9 & 14,6 & em elevação & 85,4 \\
\hline 1994 & 5,9 & 14,2 & $\begin{array}{l}\text { em elevação (até junho) } \\
\text { em queda (após junho) }\end{array}$ & 61,5 \\
\hline 1995 & 4,2 & 13,2 & em queda & 54,6 \\
\hline 1996 & 2,8 & 15,1 & em queda & 64,7 \\
\hline 1997 & 3,7 & 16,0 & em queda & 49,7 \\
\hline 1998 & 0,1 & 18,2 & próxima de zero & 67,2 \\
\hline 1999 & 0,8 & 19,3 & elevada & 64,1 \\
\hline 2000 & 4,4 & 17,6 & em queda & 54,7 \\
\hline 2001 & 1,3 & 17,6 & em elevação & 42,3 \\
\hline 2002 & 2,7 & 19,0 & elevada & 80,9 \\
\hline 2003 & 1,1 & 19,9 & elevada (+ de 10\% a.a.) & 88,0 \\
\hline 2004 & 5,7 & 18,7 & estável (- de $8 \%$ a.a.) & \\
\hline 2005 & 2,9 & 16,9 & em queda & 96,3 \\
\hline 2006 & 3,7 & 15,8 & em queda & \\
\hline
\end{tabular}

Quadro 1 - Conceitos para análise das negociações coletivas.

A leitura conjunta desses quatro elementos auxilia na compreensão dos movimentos e objetivos dos participantes da negociação coletiva.

\section{Um breve olhar sobre os anos 1990}

Ao final da década de 1990, o quadro das negociações coletivas alterou-se bastante relativamente ao que se conheceu nos anos 1980. Do ponto de vista de suas estruturas, consolidou-se fortemente a tendência de sua descentralização, principalmente na área da indústria. Como exemplo, na Federação das Indústrias do Estado de São Paulo (FIESP), a principal federação industrial patronal do País, já não havia mais lugar para a grande mesa negociadora do acordo de data-base do setor metalúrgico do fim dos anos 1980. Em seu lugar, existiam negociações coletivas, por meio de blocos distintos, como os formados pelos setores da fundição, autopeças, máquinas, equipamentos etc. Além disso, com a proliferação dos acordos de participação nos lucros e resultados (PLR) e outros, as próprias empresas passaram a constituir unidades de negociação cuja existência e consolidação até então eram inéditas.

Em outro aspecto vinculado à estrutura das negociações coletivas, vale destacar a reorganização que se inicia nos setores privatizados. As negociações, que nesses setores ocorriam de forma centralizada e quase sempre nacional com holdings estatais federais (como no ramo de telecomunicações ou de energia), passaram a acontecer de maneira local ou regionalizada com as novas empresas constituídas após a privatização.

Como outros exemplos de mudanças expressivas em termos das estruturas de negociação, podem ser apontados setores como o das montadoras de automóveis ou da siderurgia, em que as empresas, por uma série de razões, decidiram abrir novas plantas em outros Estados. Nesses casos, as empresas que já atuavam em mercados de produto de 
dimensões nacionais ou mesmo internacionais começaram a operar dentro das oportunidades oferecidas pelo mercado de trabalho nacional. Além do interesse nas vantagens logísticas dos novos empreendimentos, existiam estímulos de natureza fiscal (normalmente oferecidos pelos governos estaduais) e também a possibilidade de contratações com menores custos entre os trabalhadores das novas plantas. Diante disso, os sindicatos passaram a se mobilizar em busca de uma estrutura de organização capaz de buscar a negociação com essas empresas dentro de uma lógica nacional. Com uma negociação nacional, os sindicatos tentariam a diminuição das diferenças de remuneração existentes entre as diversas plantas pertencentes às empresas no território nacional ${ }^{4}$ (ZYLBERSTAJN, 2003, p. 297).

Do ponto de vista dos processos de negociação, a postura defensiva foi a determinante no período, o que se espelha na redução do número de greves entre as diversas categorias. Com o surgimento de itens negociados - como a PLR, banco de horas e outros relacionados às condições de contratação - novos processos foram sendo experimentados no que se refere ao momento das negociações que não mais se prendeu ao tradicional período da data-base.

Além disso, os processos negociais também apresentaram novidades quanto ao próprio comportamento dos participantes das mesas de negociação. Uma vez que as negociações começaram a acontecer mais frequentemente no nível das empresas e que os temas se vinculavam ao seu desempenho e condições para superação de metas, boa parte das negociações transcorreu sob o ambiente do chamado "ganha-ganha", ou seja, dentro de um ambiente mais cooperativo do que de confronto. A baixa proporção de greves, motivadas pela PLR, reforça a hipótese da pequena presença de conflitos nesses processos negociais (DIEESE, 2001a).

No que se refere aos conteúdos das negociações, as mudanças também foram expressivas. A partir da análise dos textos dos acordos, Oliveira (2003, p. 281) aponta a supressão das cláusulas relativas à indexação salarial como a principal mudança, que pretendia repor perdas salariais passadas nos textos dos acordos coletivos. Para esse autor, as cláusulas relativas à PLR passaram a ocupar "de maneira parcial e insatisfatória" o lugar das normas de reajustes salariais.

O DIEESE (2001a, p. 202) tem opinião semelhante e destaca o redirecionamento das garantias dadas à remuneração no corpo dos acordos coletivos. Com o fim das políticas salariais e o surgimento da PLR, houve um deslocamento da regulação da remuneração da parte fixa (o salário propriamente dito) para uma parte variável. A partir de meados dos anos 90, a produtividade tornou-se item tratado no âmbito das negociações de PLR, logo, um item de valor variável e, por consequência, não incorporado à remuneração..

Os dados obtidos a partir dos acordos coletivos mostram que os reajustes salariais deixaram de acompanhar obrigatoriamente a inflação do período, concretizando, assim, a desindexação pretendida quando do lançamento do Plano Real em 1994. Na Tabela 1, percebese que a proporção de acordos que igualaram ou superaram a inflação declinou entre 1995 e 1999. O ano mais crítico dessa etapa foi justamente 1999, quando, juntamente com o baixo crescimento econômico, houve ainda o retorno da inflação. Na pesquisa realizada pelo DIEESE (2000), apenas 49,7\% dos acordos coletivos tiveram reajustes iguais ou superiores à inflação.

\footnotetext{
${ }^{4}$ Em 1999, sindicatos metalúrgicos da CUT e Força Sindical organizaram um movimento conjunto chamado "Festival de Greves". Dentro desse "Festival" foram realizadas greves e manifestações em São Paulo, Paraná e Minas Gerais com o objetivo de pressionar as montadoras a negociar uma convenção coletiva nacional (RODRIGUES, 2002, p. 143).
} 
Tabela 1- Dados relevantes para as negociações coletivas no Brasil ${ }^{5}$

\begin{tabular}{c|l|l|l|c}
\hline Ano & $\begin{array}{c}\text { PIB - } \\
\text { Crescimento } \\
\text { (anual) (\%) (1) }\end{array}$ & $\begin{array}{c}\text { Desemprego } \\
\text { Total -RMSP } \\
(\mathbf{2})\end{array}$ & $\begin{array}{c}\text { Inflação (tendência } \\
\text { ao longo do ano) } \\
\text { (3) }\end{array}$ & $\begin{array}{c}\text { Reajustes } \\
\text { salariais iguais } \\
\text { ou superiores ao } \\
\text { INPC/IBGE (4) } \\
\text { (\%) }\end{array}$ \\
\hline 1990 & $-4,4$ & 10,3 & em elevação & Nd \\
\hline 1991 & 1,0 & 11,7 & em elevação & Nd \\
\hline 1992 & $-0,5$ & 15,2 & em elevação & Nd \\
\hline 1993 & 4,9 & 14,6 & em elevação & 85,4 \\
\hline 1994 & 5,9 & 14,2 & $\begin{array}{l}\text { em elevação (até junho) } \\
\text { em queda (após junho) }\end{array}$ & 61,5 \\
\hline 1995 & 4,2 & 13,2 & em queda & 54,6 \\
\hline 1996 & 2,8 & 15,1 & em queda & 64,7 \\
\hline 1997 & 3,7 & 16,0 & em queda & 49,7 \\
\hline 1998 & 0,1 & 18,2 & próxima de zero & 67,2 \\
\hline 1999 & 0,8 & 19,3 & elevada & 64,1 \\
\hline 2000 & 4,4 & 17,6 & em queda & 54,7 \\
\hline 2001 & 1,3 & 17,6 & em elevação & 42,3 \\
\hline 2002 & 2,7 & 19,0 & elevada & 80,9 \\
\hline 2003 & 1,1 & 19,9 & elevada (+ de $10 \%$ a.a.) & 88,0 \\
\hline 2004 & 5,7 & 18,7 & estável (- de $8 \%$ a.a.) & 96,3 \\
\hline 2005 & 2,9 & 16,9 & em queda & \\
\hline 2006 & 3,7 & 15,8 & em queda & \\
\hline
\end{tabular}

Fonte: ANOTE n. 37 in www.dieese.org.br, (1) IBGE, (2) taxa média anual da Região Metropolitana de São Paulo - PED DIEESE/SEADE, (3) e (4) DIEESE - percentual refere-se ao total de acordos coletivos. Elaboração do autor.

No que se refere ao conjunto das cláusulas dos acordos, a percepção é de que, nesta etapa, houve uma grande pressão sobre o seu conteúdo. Oliveira (2003), DIEESE (1999) e Prado (1998) trabalharam com conjuntos de acordos de diversas categorias e chegaram a conclusões semelhantes nesse aspecto. De maneira geral, a tendência identificada na década de 1980 foi a ampliação da cobertura dos textos dos acordos. Em contraponto, nos anos 1990, os acordos de boa parte das categorias deixaram de crescer, quando não encolheram em número de cláusulas e conteúdo favorável aos trabalhadores.

Da parte dos sindicatos, questões importantes para as negociações coletivas dos anos 1990, como as relacionadas às mudanças nos processos produtivos e seus impactos sobre os trabalhadores - as mais objetivamente vinculadas ao emprego ou mesmo em relação à qualificação dos trabalhadores -, tornaram-se pontos de pauta entre as reivindicações apresentadas aos patrões. Entretanto, de maneira geral, a presença de cláusulas tratando desses temas nos acordos coletivos foi bem escassa nesse período. As cláusulas existentes a respeito desses assuntos tinham, quando muito, aspectos defensivos, com o objetivo de conceder garantias adicionais a trabalhadores demitidos (DIEESE, 1999, p. 59).

Tal comportamento aponta, de forma inequívoca, uma perda do poder regulatório dos sindicatos no que se refere à contratação do trabalho e sintetiza, a partir dos resultados das negociações, o difícil quadro enfrentado por essas entidades na representação dos trabalhadores ao longo desse período.

\footnotetext{
${ }^{5}$ O DIEESE reúne regularmente os dados relativos aos reajustes salariais em painéis com grande número de acordos. Os dados, portanto, não possuem o rigor técnico de amostras preparadas estatisticamente, mas permitem a aferição de grandes tendências para as negociações.
} 


\section{Análise geral do período 2000 a 2006}

Nessa etapa, as negociações coletivas passaram por uma espécie de acomodação a todas as transformações iniciadas nos anos 1990. De uma forma geral, do ponto de vista das estruturas de negociação, as mudanças identificadas nos anos anteriores continuaram em andamento, tanto no que se refere à descentralização rumo às empresas, quanto aos movimentos de reorganização em setores privatizados ou que passaram por redistribuição de plantas produtivas no território nacional. Nesses casos, tratou-se de negociações em que a própria estrutura de negociação tornou-se objeto de barganha entre as partes.

Outra característica desse período foram as tentativas de campanhas salariais conjuntas entre os sindicatos pertencentes às diferentes centrais sindicais (principalmente a CUT e a Força Sindical) com a intenção de somar forças e superar o pano de fundo adverso às negociações. Essas iniciativas ocorreram, normalmente, no segundo semestre de alguns anos, quando categorias de grande visibilidade (como metalúrgicos, químicos e trabalhadores da alimentação no Estado de São Paulo, e categorias nacionais como bancários e petroleiros, por exemplo) realizaram suas campanhas salariais (RODRIGUES, 2002). Nesses momentos, as entidades sindicais buscaram discutir calendários comuns de mobilização para pressionar os patrões. Normalmente esses movimentos mantiveram a característica de mobilização conjunta apenas no começo das campanhas e nas mobilizações de rua. Passada essa primeira etapa, as campanhas e suas respectivas negociações voltavam à dinâmica própria de cada categoria.

\begin{tabular}{|l|l|}
\hline Contexto & $\begin{array}{l}\text { Instabilidade econômica: stop and go, baixa taxa média de crescimento econômico e desemprego elevado } \\
\text { •2000: economia aquecida e início de recuperação } \\
\text { •2001: crise energética e internacional } \\
\text { •2002: instabilidade do Real e volta da inflação } \\
\text { •2003: recessão e inflação pela primeira vez acima dos } 10 \% \text { anuais } \\
\text { •2004: retorno do crescimento econômico }\end{array}$ \\
\hline Estrutura & $\begin{array}{l}\text { Tendências mantidas: a) Descentralização das negociações (rumo às empresas); b) Setores privatizados: alteração } \\
\text { das estruturas de negociação } \\
\text { Tentativas sindicais de campanhas conjuntas }\end{array}$ \\
\hline Processo & $\begin{array}{l}\text {-2000: negociações menos truncadas } \\
\text {-2001 e 2002: negociações defensivas e truncadas } \\
\text { 2003: Fevereiro a abril: negociações de antecipações salariais fora da data-base. Restante do ano: retorno às } \\
\text { negociações defensivas }\end{array}$ \\
\hline $\begin{array}{l}\text { •tentativa de renovação dos acordos por parte dos sindicatos } \\
\text { 2003: antecipações salariais (no começo do ano); parcelamento de reajustes na data-base } \\
\text { existência de abonos; escalonamento } \\
\text { 2004 a 2006: retorno dos acordos com reajustes salariais com grande proporção de acordos iguais ou acima da } \\
\text { inflação }\end{array}$ \\
\hline
\end{tabular}

Fonte: Elaboração do autor

Quadro 2 - Período 2000/2004.

Do ponto de vista dos processos de negociação, as campanhas salariais, em anos de pequeno crescimento econômico como 2001 a 2003, caracterizaram-se por rodadas truncadas e com pouco espaço para avanços nos acordos. Vale apontar, ainda, que, nos momentos econômicos mais difíceis, as concessões constantes dos acordos não foram exclusividade de grupos de sindicatos pertencentes a uma única central. Os sindicatos das principais centrais divergiram politicamente entre si sobre os termos aceitos nos acordos assinados nesses períodos mais difíceis, mas, de maneira geral, prevaleceu entre eles o pragmatismo como orientação nas negociações.

A novidade desse período consistiu no surgimento de negociações fora de data-base para a obtenção de antecipações ou compensações para as perdas salariais impostas pela 
inflação no começo de 2003. Naquela ocasião, a inflação, acumulada entre novembro de 2002 e o início de 2003, superou os reajustes salariais que as categorias haviam recebido em suas datas-base no segundo semestre de 2002. Isto levou os sindicatos a pressionarem, principalmente as empresas, a fim de obterem antecipações salariais,.

A negociação de antecipações salariais fora da data-base foi prática comum quando a indexação geral da economia estava associada ao crescimento da inflação, como nas negociações coletivas do período pré-real. Por isso, naquele momento, o reaparecimento desse tipo de negociação evocou os antigos fantasmas de retorno da inflação pela via de uma possível reindexação salarial. O número de negociações salariais por antecipações ou compensações frente à inflação foi significativo, e os exemplos podiam ser encontrados principalmente entre empresas na área da indústria paulista. Todavia, a reindexação salarial não se confirmou. O primeiro quadrimestre de 2003 foi apenas um interregno no qual houve negociações em que os sindicatos foram um pouco mais agressivos no que se refere às perdas salariais. No restante do ano, houve o retorno das negociações salariais defensivas e centradas na data-base das categorias. Premida pela queda na renda real média e pela manutenção de juros elevados patrocinada pelo governo, a economia reingressou em novo período recessivo ao longo de 2003, que só foi parcialmente superado em 2004.

Os dados existentes sobre os movimentos grevistas reforçam a percepção do caráter defensivo adquirido pela postura sindical nas negociações coletivas entre 2001 e 2003. A Tabela 2 demonstra que de 2000 em diante há uma tendência de queda, tanto no número de greves registradas quanto no número de trabalhadores envolvidos nessas greves, denotando a perda de capacidade de mobilização dos sindicatos.

A análise dos resultados das negociações coletivas desse período indica que, do ponto de vista da remuneração, houve grande oscilação em termos dos reajustes conquistados pelas categorias. Essa oscilação, de certa forma, acompanhou as combinações de dois indicadores importantes da economia: o crescimento econômico e a inflação. Assim, em anos de crescimento econômico um pouco mais expressivos e inflação estável ou em queda, a proporção de acordos coletivos que alcançaram ou superaram a inflação foi mais elevada, como em 2000, 2004, 2005 e 2006. A exceção seria 2001, mas deve-se considerar que, pelo menos, até o mês de maio, a economia brasileira manteve-se na trajetória de crescimento desenhada no ano anterior, o que favoreceu a negociação dos reajustes durante essa parte do ano.

Em 2002 e 2003, a combinação de baixo crescimento econômico e inflação elevada produziu contextos difíceis para as negociações salariais, o que se espelha nas baixas proporções de acordos cujos reajustes igualaram ou superaram a inflação do período. Principalmente nesses anos, prevaleceu da parte dos sindicatos a tentativa de renovação, vale dizer, a manutenção dos textos dos acordos de anos anteriores. Em outras palavras, tratou-se, nesses anos, de tentar garantir os patamares de regulação conquistados em anos anteriores.

Em outro aspecto a ser destacado, a presença de elementos flexibilizadores da remuneração consolidou-se ainda nos textos dos acordos. Desde 1999, itens como abonos salariais, parcelamentos de reajustes ou mesmo escalonamentos de reajustes tornaram-se parte do cardápio da negociação em torno da remuneração. Entre 10 e 25\% dos acordos a cada ano continham algum tipo de cláusula neste sentido (DIEESE, 2006) 
Tabela 2 - Número anual de greves, número e média de grevistas

\begin{tabular}{c|c|c|c}
\hline \multirow{2}{*}{ Ano } & \multirow{2}{*}{$\mathbf{N}^{\circ}$ de greves } & \multicolumn{2}{|c}{$\mathbf{N}^{\circ}$ de grevistas } \\
\cline { 3 - 4 } & & Total & Média por Greve \\
\hline $\mathbf{1 9 9 0}$ & 1.789 & 7.702 .954 & 4.306 \\
\hline $\mathbf{1 9 9 1}$ & 1.054 & 5.799 .608 & 5.502 \\
\hline $\mathbf{1 9 9 2}$ & 556 & 2.616 .715 & 4.706 \\
\hline $\mathbf{1 9 9 3}$ & 644 & 3.117 .982 & 2.842 \\
\hline $\mathbf{1 9 9 4}$ & 1.043 & 2.542 .911 & 2.438 \\
\hline $\mathbf{1 9 9 5}$ & 1.056 & 2.283 .114 & 2.162 \\
\hline $\mathbf{1 9 9 6}$ & 1.242 & 2.482 .528 & 1.299 \\
\hline $\mathbf{1 9 9 7}$ & 633 & 808.495 & 2.315 \\
\hline $\mathbf{1 9 9 8}$ & 536 & 1.241 .080 & 2.567 \\
\hline $\mathbf{1 9 9 9}$ & 507 & 1.301 .656 & 7.262 \\
\hline $\mathbf{2 0 0 0}$ & 526 & 3.819 .586 & 2.018 \\
\hline $\mathbf{2 0 0 1}$ & 420 & 847.639 & 4.006 \\
\hline $\mathbf{2 0 0 2}$ & 304 & 1.217 .865 & 5.735 \\
\hline $\mathbf{2 0 0 3}$ & 340 & 1.949 .747 & 4.276 \\
\hline $\mathbf{2 0 0 4}$ & 302 & 1.291 .332 & 6.579 \\
\hline $\mathbf{2 0 0 5}$ & 299 & 1.967 .000 & \\
\hline
\end{tabular}

Nota: dados preliminares, sujeitos a revisão.

Fonte: SAG-DIEESE (2007).

\section{As negociações coletivas brasileiras e suas tendências}

O quadro geral das negociações coletivas transformou-se profundamente dos anos 1990 em diante. Ao longo da década de 1980, o ambiente inflacionário, a constante mudança de regras salariais e menores taxas de desemprego foram ingredientes de negociações que, não raro, motivavam grandes mobilizações por parte dos sindicatos. Já da década de 1990 em diante - citando apenas três diferenciadores mais diretamente vinculados às negociações coletivas - a queda da inflação, o término das políticas salariais (que previam reajustes automáticos) e o crescimento do desemprego combinaram-se e contribuíram para a desmobilização dos trabalhadores em suas campanhas. A estes elementos somaram-se outros, como a abertura econômica, as privatizações e os processos de reestruturação produtiva que as empresas realizaram para se ajustar às novas condições da economia brasileira. A continuidade desse quadro geral aponta tendências para as negociações coletivas brasileiras, como as destacadas sinteticamente na Tabela 3.

A atual política econômica, mesmo sob governos diferentes, vem sendo praticada sem grandes alterações nas suas linhas principais. Com isso, na hipótese de que não acontecerão mudanças expressivas no futuro próximo, é plausível considerar que, especialmente no aspecto da remuneração, a negociação coletiva continue condicionada às condições macroeconômicas de crescimento econômico e dos preços. Com a política econômica focada, prioritariamente, na estabilidade de preços, as variáveis relacionadas ao mercado de trabalho permanecem como instrumentos de ajuste da economia. Em outras palavras, a cada surto de crescimento da inflação, uma nova elevação de juros é promovida, advindo uma nova elevação do desemprego e crescentes dificuldades dos sindicatos no que se refere à manutenção dos salários reais. Para as empresas, isso significa a possibilidade de ajustes através do corte de custos nas folhas de pagamento.

Uma dimensão do tipo de ajuste realizado em termos da remuneração pode ser encontrada nas características dos acordos coletivos em termos de suas cláusulas de reajustes salariais segundo os setores econômicos e as regiões do País. Na Tabela 3, verifica-se que, ao 
longo dos anos e desenhando uma tendência consolidada, os acordos na indústria são mais bem-sucedidos que nos demais setores, cabendo ao setor de serviços os acordos com menores reajustes salariais.

O setor de serviços é extremamente diversificado, já que envolve atividades vinculadas aos transportes, comunicações, serviços financeiros, alimentação, alojamento, cuidados com pessoas, empresas e órgãos públicos etc. Ao longo da década de 1990, este setor, acompanhando a tendência geral entre os países, cresceu entre as atividades urbanas no Brasil. Criando 87\% das novas ocupações do período até 2001, o setor de serviços era responsável por mais da metade das ocupações e da renda urbana (BALTAR, 2005, p. 58).

Entretanto, dado o baixo crescimento econômico do País nos últimos quinze anos, a expansão geral do número de ocupações - e neste caso, certamente, também do setor de serviços - ocorreu com aumento das ocupações por conta própria, no emprego nas pequenas empresas e no serviço doméstico remunerado, vale dizer, em áreas nas quais os vínculos formais de contratação são menos presentes (BALTAR, 2005, p. 54).

A possibilidade de o setor de serviços apresentar indicadores mais favoráveis no que se refere aos reajustes salariais constantes nos seus acordos depende de uma recuperação da renda. Os serviços e o comércio estão diretamente relacionados à variação da renda, e esta, por sua vez, atrela-se a um maior crescimento geral da economia. O que parece ser o caso do que se observa em 2006.

No caso da indústria, além da retomada do crescimento econômico, a competitividade do setor - que pode ser afetada pelos ganhos de produtividade e pelas oscilações do câmbio - são as grandes condicionantes do seu desempenho e consequente capacidade de pagar melhores salários.

Na Tabela 4, encontram-se dados referentes aos acordos salariais segundo as regiões do País. As regiões Sul e Sudeste, nessa ordem, apresentam a maior proporção de reajustes salariais acordados iguais ou acima da inflação ao longo do tempo, e a região Nordeste é a que possui os menores indicadores. Nesta região, onde, comparativamente às demais, são encontradas as maiores taxas de desemprego e menores salários médios, a flexibilidade na remuneração aparece mais consistentemente ao longo dos anos.

Tabela 3 - Proporção de reajustes anuais iguais ou acima da inflação (INPC) ${ }^{6}$ (\%)

\begin{tabular}{l|c|c|c|c|c|c|c|c}
\hline Setores & $\mathbf{1 9 9 9}$ & $\mathbf{2 0 0 0}$ & $\mathbf{2 0 0 1}$ & $\mathbf{2 0 0 2}$ & $\mathbf{2 0 0 3}$ & $\mathbf{2 0 0 4}$ & $\mathbf{2 0 0 5}$ & $\mathbf{2 0 0 6}$ \\
\hline Indústria & 46,8 & 70,0 & 66,3 & 64,7 & 55,4 & 87,1 & 93,5 & 97,0 \\
\hline Comércio & 85,3 & 50,0 & 66,6 & 62,7 & 44,4 & 82,4 & 93,3 & 96,5 \\
\hline Serviços & 41,8 & 62,9 & 57,0 & 31,2 & 25,9 & 71,5 & 79,7 & 95,8 \\
\hline Geral & $\mathbf{4 9 , 7}$ & $\mathbf{6 7 , 2}$ & $\mathbf{6 4 , 8}$ & $\mathbf{5 4 , 7}$ & $\mathbf{4 2 , 3}$ & $\mathbf{8 0 , 9}$ & $\mathbf{8 8 , 0}$ & $\mathbf{9 6 , 4}$ \\
\hline
\end{tabular}

Fonte: Tabela elaborada pelo autor, com base nos dados do DIEESE - Balanço das Negociações (diversos anos).

6 Idem nota 6. 
Tabela 4 - Proporção de reajustes anuais iguais ou acima da inflação (INPC) ${ }^{7}(\%)$

\begin{tabular}{l|c|c|c|c|c|c|c|c}
\hline Regiões & $\mathbf{1 9 9 9}$ & $\mathbf{2 0 0 0}$ & $\mathbf{2 0 0 1}$ & $\mathbf{2 0 0 2}$ & $\mathbf{2 0 0 3}$ & $\mathbf{2 0 0 4}$ & $\mathbf{2 0 0 5}$ & $\mathbf{2 0 0 6}$ \\
\hline Nordeste & - & 67,5 & 54,3 & 38,7 & 24,7 & 72,7 & 76,6 & 98,3 \\
\hline Sudeste & - & 70,4 & 60,7 & 51,3 & 42,1 & 80,5 & 92,5 & 97,1 \\
\hline Sul & - & 66,6 & 81,3 & 76,3 & 60,0 & 87,5 & 89,9 & 95,4 \\
\hline Geral & $\mathbf{4 9 , 7}$ & $\mathbf{6 7 , 2}$ & $\mathbf{6 4 , 8}$ & $\mathbf{5 4 , 7}$ & $\mathbf{4 2 , 3}$ & $\mathbf{8 0 , 9}$ & $\mathbf{8 8 , 0}$ & $\mathbf{9 6 , 4}$ \\
\hline
\end{tabular}

Fonte: Tabela elaborada pelo autor, com base nos dados do DIEESE - Balanço das Negociações (diversos anos).

Os dados apresentados reforçam a impressão de que as negociações coletivas brasileiras, pelo menos quanto aos aspectos dos reajustes salariais, não compõem um todo homogêneo, principalmente nos períodos de instabilidade econômica. Mais recentemente, de 2004 a 2006, a combinação de fatores no ambiente das negociações coletivas, como inflação reduzida e crescimento econômico, elevou a proporção de reajustes salariais acordados que se igualaram ou mesmo superaram a inflação em todas as regiões e setores econômicos. Isso fez com que a diferenciação dos reajustes salariais diminuísse.

Dessa maneira, com base nas Tabelas 3 e 4, percebe-se que a diferenciação dos salários, seja em termos setoriais, seja em termos regionais, é um fenômeno possível a depender da combinação dos índices de inflação e crescimento econômico. Quando a inflação mostrou-se mais elevada e o crescimento econômico menor, a diferenciação surgiu. Já no período 2004 a 2006, quando a inflação declinou e houve discreto crescimento econômico, esta diferenciação diminuiu.

Em outro aspecto importante, cabe assinalar a atual situação da estrutura sindical. Conforme destaca Castro (2004, p. 5-6), a Constituição de 1988 fortaleceu o sindicalismo, pois

o processo de criação e de funcionamento dos sindicatos deixou de ter interferência do Ministério do Trabalho, a obrigatoriedade de participação dos sindicatos nas negociações coletivas passou a ser um direito constitucional e se garantiu o direito de organização dos funcionários públicos.

Porém, a ambiguidade do texto constitucional (especialmente no artigo $8^{\circ}$, que trata da liberdade e unicidade sindical) abriu a possibilidade de multiplicação de entidades sindicais. Com isto, segundo a Pesquisa Sindical do IBGE, em 2001, já eram mais de 11,3 mil entidades de trabalhadores, existindo informações de que este número deve crescer ainda mais ${ }^{8}$. Parcela do crescimento do número de entidades sindicais pode ser debitada às organizações do funcionalismo público, que só então puderam se constituir legalmente ${ }^{9}$. Na larga maioria dos casos, porém, as novas entidades surgiram sem representatividade.

\footnotetext{
7 Ibidem.

${ }^{8}$ Castro (2004, p. 11) elenca uma série de hipóteses para esta expansão do número de sindicatos: deslocamento de grandes empresas para regiões do interior que antes integravam bases de outros sindicatos; busca de estabilidade laboral para um maior número de militantes; acesso a eleições de juízes classistas; divergências políticas e/ou disputas pessoais de poder; acesso a programas de formação profissional financiados pelo CODEFAT e outros.

${ }_{9}^{9}$ Segundo Almeida (1998, p. 6), cerca de um quarto dessas novas entidades seria de funcionários públicos.
} 
A pulverização da representação dos trabalhadores, encontrada até mesmo no número de centrais sindicais, ocorreu concomitantemente a uma queda no nível geral de sindicalização. Dados do IBGE apontam que a taxa de sindicalização, que chegou a 32\% da população economicamente ativa em 1989, restringia-se apenas a 17,7\% em 2003 (DIEESE, 2005, p. 174). A queda do número de greves e de grevistas, acontecida desde os anos 1990, muito provavelmente também se vinculou a esse fato.

O efeito combinado do aumento do número de sindicatos e da queda da sindicalização promoveu mais dificuldades para as condições de mobilização dos trabalhadores, já que se multiplicaram também os conflitos intersindicais pela representação dos trabalhadores. Enquanto este processo de expansão de novas entidades sindicais não se esgotar e a baixa sindicalização não for revertida, prevalecerá um cenário sindical de dispersão da energia necessária para a condução das campanhas e negociações tanto no nível mais baixo da estrutura sindical (sindicatos e federações) quanto no seu topo (as centrais).

No que se refere às centrais sindicais, as chamadas negociações institucionais tornaram-se parte perceptível das agendas sindicais na década de 1990. A permanência e importância dessa agenda estão vinculadas a pelo menos dois aspectos. O primeiro deles é a própria disposição dos governos de preservar estes fóruns de discussão nos quais o movimento sindical tem sido chamado a tomar assento. A câmara setorial da indústria automobilística que, como fórum tripartite, estruturou-se durante o governo Itamar Franco, é um exemplo. Durante seu funcionamento, o tipo de negociação praticada na câmara setorial oxigenou as relações trabalhistas entre empresas e sindicatos, mas foi abandonada no governo Fernando Henrique, sem se generalizar para outros setores econômicos.

O segundo aspecto refere-se à efetividade desses fóruns como geradores de decisões ou orientações de real alcance em termos de políticas e uso de recursos públicos. Aqui serve como exemplo das negociações em torno do uso de recursos do Fundo de Amparo aos Trabalhadores (FAT). Durante a segunda metade da década de 1990, houve negociações no âmbito do Conselho Deliberativo do FAT (CODEFAT) em torno do uso de recursos do fundo para que as entidades sindicais promovessem atividades de formação e intermediação de mão de obra.

Já, nos anos mais recentes, esses recursos deixaram de ser disponíveis na proporção anteriormente verificada, gerando descontinuidade nos programas executados pelas entidades sindicais.

\begin{tabular}{|l|l|}
\hline Contexto & $\begin{array}{r}\text { Condicionamento das negociações: } \\
\text { campanhas salariais pelo ritmo de crescimento da economia e controle da inflação; } \\
\text { negociações institucionais pelo grau de abertura dos governos à participação do movimento } \\
\text { sindical na discussão de políticas públicas; } \\
\text { negociações internacionais de acordo com o ritmo de abertura e intercâmbio da economia } \\
\text { brasileira; } \\
\text { Estrutura }\end{array}$ \\
$\begin{array}{l}\text { a espera da reforma sindical e trabalhista: transição. } \\
\text { Negociações centralizadas: representação institucional (políticas públicas) através das centrais sindicais } \\
\text { Negociações descentralizadas por empresas, mas com representação unificada de sindicatos nacionais, } \\
\text { estrangeiros e internacionais: para as negociações internacionais (integração econômica, empresas } \\
\text { multinacionais e empresas brasileiras no exterior). }\end{array}$ \\
\hline Processo & $\begin{array}{l}\text { Novos processos de negociação: negociações internacionais, novos temas. } \\
\text { Presença esporádica da Justiça do Trabalho (desregulando a contratação coletiva). }\end{array}$ \\
\hline Conteúdo & Novos temas: raça, gênero, deficientes, códigos de conduta, responsabilidade social. \\
\hline
\end{tabular}

Elaboração do autor.

Quadro 3 - Tendências para as negociações coletivas. 
Ainda no que se refere ao contexto das negociações, vale destacar a influência que o grau de abertura da economia brasileira pode exercer sobre as negociações coletivas. A exploração das características da ação sindical quanto à dimensão internacional das negociações coletivas não faz parte dos objetivos deste trabalho ${ }^{10}$. Entretanto, a partir da década de 1990, diversos fenômenos levaram a negociação coletiva a ser pensada como algo a ser tratado internacionalmente. Dentro do contexto mais amplo da globalização, em primeiro lugar, houve o aumento da presença de empresas estrangeiras dos anos 1990 em diante por conta do rearranjo patrimonial ao qual as empresas atuantes no Brasil (aí incluídas as empresas privatizadas) se submeteram. A chegada destas novas empresas estrangeiras reforçou os contatos entre as entidades sindicais brasileiras e as de outros países, ou mesmo com os ramos sindicais da principal central sindical internacional, a Confederação Sindical Internacional (CSI). ${ }^{11} \mathrm{O}$ estabelecimento destes contatos tem resultado em programas conjuntos de intensa cooperação internacional entre os sindicatos. Além da intensificação da presença estrangeira no Brasil, há como fato novo o estabelecimento de grandes empresas brasileiras em outros países. ${ }^{12}$ Neste momento, a busca de cooperação ocorre com sinal invertido, ou seja, a partir do movimento sindical dos países onde estas empresas passam a atuar. Nos dois casos, a intenção sindical é equilibrar as condições de contratação do trabalho entre os diversos países.

O âmbito internacional inclui ainda as questões relacionadas à formação de blocos econômicos e os seus impactos sobre os trabalhadores. Como arranjos internacionais, os blocos são compostos a partir de negociações comerciais e diplomáticas, complexas e demoradas, e a diferença de posição dos diversos países também se reflete no posicionamento das entidades sindicais.

A formação e consolidação de blocos econômicos podem atingir os trabalhadores pelas possibilidades de importação de produtos mais baratos ou pelo deslocamento de plantas produtivas entre os países em busca de menores custos operacionais. Assim, as centrais sindicais brasileiras têm buscado interferir nesses processos por meio de comissões, como a Coordenadora Sindical do Mercosul ou de instâncias como a Aliança Social para as Américas, na qual a ALCA é o grande assunto. O desafio sindical é elaborar um discurso e ação que unifiquem as posições dos trabalhadores nos diversos países.

Mantido ou intensificado o atual ritmo de abertura da economia brasileira e seu envolvimento com a economia globalizada, é de se esperar a tentativa de estruturação de negociações coletivas articuladas internacionalmente com outras entidades sindicais juntamente às empresas, assim como o fortalecimento dessas instâncias internacionais de ação sindical.

A análise das tendências para as negociações coletivas aponta para dois extremos em termos de estrutura, processos e conteúdos. No âmbito mais tradicional das negociações coletivas, encontram-se as negociações coletivas de data-base cujo andamento e resultado são condicionados pela conjuntura econômica e, mais especificamente, pelo mercado de trabalho. Não havendo reversão brusca do atual contexto (por exemplo, com retorno da espiral inflacionária), devem ser mantidas as tendências, até aqui observadas, de descentralização das negociações, flexibilização salarial e pressão por redução no grau de cobertura dos acordos em termos de garantias no corpo dos acordos.

\footnotetext{
${ }^{10}$ Chaloult e Brunelle (1998) oferecem interessante referencial teórico para apreciação da ação sindical internacional.

11 A CSI surgiu em novembro de 2006 quando da fusão entre a Confederação Internacional das Organizações Sindicais Livres (CIOSL) e a Confederação Mundial do Trabalho (CMT).

${ }^{12}$ A título de exemplo, nos últimos anos, a Petrobras tem estendido sua atuação a países da América do Sul, e a Gerdau tem comprado plantas siderúrgicas nos Estados Unidos.
} 
Em outro extremo, em um contexto mais sofisticado estão as negociações de cunho institucional, cujo leque temático é bastante amplo e pode conter pontos como determinação do valor do salário mínimo, integração de blocos econômicos, políticas públicas de emprego como intermediação e qualificação etc. Neste mesmo bloco de negociações mais complexas estão também aquelas vinculadas às empresas multinacionais, aí incluídas as brasileiras.

Cabe ainda destacar a emergência de temas cuja abordagem nas negociações coletivas vem ganhando maior consistência nos últimos anos. Entre esses temas, encontram-se, por exemplo, as reivindicações vinculadas à discriminação de raça, às questões de gênero ou de emprego de portadores de necessidades especiais entre as empresas. Embora presentes nas pautas de reivindicações dos sindicatos há bastante tempo, tais temas vêm recebendo maior atenção no que se refere à sua fundamentação por parte dos sindicatos. Nessas questões, as negociações vão além do tradicional embate entre capital e trabalho e chegam até à necessidade de mudanças culturais de médio para longo prazo no âmbito das empresas. Com o apoio da Organização Internacional do Trabalho (OIT) e outras organizações internacionais (como o Fundo de Igualdade de Gênero da Canadian International Development Agency (CIDA) e o Solidary Center, vinculado à central sindical norte-americana (American Federation of Labor American - Congress of Industrial Organizations - AFL-CIO) os sindicatos têm investido fortemente em atividades de pesquisa (perfis de categoria, tabulação das cláusulas existentes em acordos e formas de mobilização e negociação) e formação específica nesses temas junto aos seus trabalhadores e dirigentes..$^{13}$ Os relatos de negociação sobre esses temas registram a resistência inicial das empresas e sindicatos patronais no reconhecimento da existência dos problemas de discriminação de raça ou gênero, por exemplo. Após o confronto com as informações, as empresas tendem a creditar eventuais diferenças nas formas de contratação entre seus trabalhadores a aspectos estruturais do mercado de trabalho. A tarefa sindical passa, então, a ser a de convencimento das empresas a uma mudança de postura. Nessas negociações, é comum o surgimento de comissões envolvendo trabalhadores e empresas ou mesas específicas para o tratamento desses temas, para só então acontecer a inclusão de cláusulas no corpo dos acordos (DIEESE, 2003).

Especialmente nas maiores empresas, a pressão por maior abertura de suas informações internas tem crescido a partir da adoção de práticas como as dos códigos de conduta e elaboração de balanços sociais. No Brasil, a disseminação dos balanços sociais entre as empresas acontece a partir de modelos como os divulgados pelo Instituto Ethos ou pelo Instituto Brasileiro de Análises Sociais e Econômicas (IBASE) que preveem a apresentação de perfis resumidos do conjunto de seus trabalhadores. A maior disponibilidade deste tipo de informação deve abrir e manter o campo para negociações coletivas em torno desses temas.

A ampliação do leque temático que ocorreu desde os anos 1990 exigiu dos dirigentes sindicais um novo preparo para o enfrentamento de temas e situações. O movimento sindical viu-se, assim, diante da necessidade de investir em pesquisa e treinamento como forma de buscar novas alternativas e propostas no campo das negociações. Em um exemplo, o DIEESE intensificou seus programas de capacitação por meio da realização de seminários e cursos a respeito da reestruturação produtiva, do mercado de trabalho, políticas públicas e

\footnotetext{
13 A maior atenção dada a esses temas pode ser constatada, por exemplo, na criação do Instituto Sindical Interamericano pela Igualdade Racial (INSPIR) em 1995, pelas centrais sindicais brasileiras e pela AFL-CIO norteamericana. Ver Amorim (2007)
} 
do funcionamento das grandes empresas. ${ }^{14}$ Confirmadas as tendências aqui desenhadas, as exigências de formação por parte dos sindicalistas devem manter-se presentes.

\section{Conclusão}

A síntese, aqui apresentada para a negociação coletiva e por extensão para a ação sindical no Brasil dos anos 1990 para cá, revelou uma agenda negocial ampliada, para além do tradicionalmente tratado em termos da remuneração dos trabalhadores, com a incorporação de temas como a reestruturação produtiva, a integração dos blocos econômicos e o tripartismo. ${ }^{15}$ Por causa dessa agenda, surgiram novos ambientes e temas de negociação, atuando tanto nas empresas quanto nas instituições. Nesse nível, o diálogo tripartite buscou, através do diálogo com o governo, estabelecer limites às perdas impostas aos trabalhadores pela reestruturação do mercado de trabalho. Em todas essas novas negociações, houve a necessidade de adaptação das partes a uma nova cultura negocial, o que, como observa Prado (1998), cria um novo campo linguístico no meio sindical e empresarial.

Os sindicatos brasileiros mudaram sua atuação em diversos sentidos. No que se refere às negociações coletivas, principalmente na indústria, passaram a negociar mais descentralizadamente. Institucionalmente ocuparam uma série de espaços abertos pelo recuo da ação do Estado em termos de sua regulação na economia. Do ponto de vista de seus assuntos, também foram obrigados a lidar com novos temas, como o da reestruturação produtiva, emprego, flexibilização, integração econômica, formação profissional etc. Da mesma maneira, do lado patronal, diante da multiplicação de espaços de negociação coletiva, muito provavelmente deve ter aumentado a demanda por pessoal especializado em negociações junto aos trabalhadores.

Internacionalmente, quando comparadas ao movimento sindical de países em desenvolvimento, as entidades brasileiras são identificadas pela sua agilidade e capacidade de mobilização dos trabalhadores. Não fossem essas qualidades, o ajuste promovido no mercado de trabalho brasileiro desde o início dos anos 1990 teria sido ainda mais violento. Entretanto, a forte pressão ideológica, proporcionada pelo predomínio das políticas econômicas de corte neoliberal, e o baixo dinamismo da economia têm criado seguidos obstáculos à atividade sindical no Brasil.

As entidades sindicais seguem sendo elementos indispensáveis ao equilíbrio de forças no jogo social, que é sabidamente desigual. Ocorre que, institucionalmente, a antiga e antiquada legislação relacionada à estrutura sindical e aos direitos trabalhistas vem sendo alvo de uma lenta desconstrução, que ocorre tanto pela via legislativa quanto pela prática das negociações. Com isso, em vez de um todo legal coerente para reger a atividade sindical e os direitos mínimos dos trabalhadores, tem prevalecido uma orientação difusa, porém decidida, de desregulação de ambos os aspectos.

Desde a década de 1990, várias iniciativas foram tomadas com o intuito de reformar a legislação sindical de maneira integrada. Entre elas, o Fórum Nacional sobre Contrato Coletivo e Relações de Trabalho no Brasil, em 1993, e a proposta de emenda constitucional do governo Fernando Henrique de 1998.

\footnotetext{
${ }^{14}$ O DIEESE foi criado em 1955 e é sustentado e dirigido pelo movimento sindical. Na década de 1990, a organização realizou atividades formativas para milhares de dirigentes sindicais com recursos do FAT. Ver Amorim (2007).

${ }^{15}$ Ainda que com alguma defasagem, a negociação coletiva brasileira repetiu a experiência vivida em outros países. Ver Tiberi (1999), Rodrigues (1999) e Larangeira (1998).
} 
Mais recentemente, em 2004, o Fórum Nacional do Trabalho, depois de exaustivas negociações tripartites, chegou a uma proposta de reforma que foi encaminhada ao Congresso Nacional. Em seu espírito geral, a reforma proposta em 2004 buscava a valorização da negociação coletiva e da representatividade sindical através de mecanismos interessantes (MTE, 2005). No que se refere à negociação coletiva, estabelecia a arbitragem de ofertas finais para casos de impasse por parte da Justiça do Trabalho e definia o que seriam práticas antissindicais por parte das empresas. A possibilidade de solução de impasses através da arbitragem de ofertas finais tenderia a reduzir a distância - leia-se radicalidade - entre as posições apresentadas pelas partes durante o processo de negociação, o que, certamente, induziria a um melhor entendimento.

No tocante à representatividade, a proposta determinava que a exclusividade de representação por parte da entidade sindical ficaria condicionada a um nível mínimo de $20 \%$ de sindicalização entre os trabalhadores. Não alcançado este patamar, a entidade perderia seu status sindical e poderia ter sua base disputada por outras entidades. Tal mecanismo teria por objetivo o estímulo à sindicalização, o que, por sua vez, a vincularia mais diretamente à capacidade de representação por parte dos sindicatos. Isoladamente essas medidas não mudariam radicalmente a face da atividade e estrutura sindical no País, mas introduziriam mais dinamismo.

No âmbito institucional mais amplo, em que pesem a multiplicidade de espaços tripartites de negociação e a participação do movimento sindical nos debates a respeito das questões do trabalho, não há um marco claro de políticas públicas sobre a oportunidade e finalidades dessas atividades. A variedade de programas do governo voltados para questões como a da inclusão de jovens no mercado de trabalho, eliminação do trabalho infantil e do trabalho escravo e das diversas formas de discriminação do trabalho seria uma evidência disto. As discussões que vêm sendo fomentadas sob o mote do Trabalho Decente no âmbito da Organização Internacional do Trabalho (OIT) poderiam contribuir para a construção de uma visão mais articulada a respeito do tratamento a ser dado às questões do trabalho, já que, a princípio, se proporiam à constituição de um programa nacional de políticas públicas para esses temas. Especialmente no caso das negociações coletivas, a valorização expressa do diálogo social - um dos pilares do Trabalho Decente - configuraria um ponto de partida institucional interessante. ${ }^{16}$

O campo das negociações coletivas diversificou-se e exigiu intenso aprendizado dos que delas participaram nos últimos quinze anos. Dadas as tendências apresentadas, tudo indica que esse aprendizado não se esgotará tão cedo.

${ }^{16}$ Ver OIT (2001). 


\section{Referências}

ALMEIDA, Maria Hermínia Tavares. Sindicatos em tempos de reforma. São Paulo em

Perspectiva, São Paulo, v. 12, n. 1, p. 3-9, 1998.

AMORIM, Wilson A. C. de. A evolução das organizações de apoio às entidades sindicais brasileiras: um estudo sob a lente da aprendizagem organizacional. 2007, 419f. Tese (Doutorado ) - Faculdade de Economia e Administração - Universidade de São Paulo, São Paulo, 2007.

BALTAR, Paulo. Dinâmica das ocupações e dos rendimentos do trabalho no Brasil. In: DIEESE; CESIT (Orgs.). O trabalho no setor terciário: emprego e desenvolvimento tecnológico. São Paulo: DIEESE; Campinas: CESIT, 2005. p. 5566.

CARVALHO NETO, Antonio. Relações de trabalho e negociação coletiva na virada do milênio: estudo em quatro setores dinâmicos da economia brasileira. Belo Horizonte: Vozes/IRT, PUC Minas, 2001.

CASTRO, Silvia P. Situação atual e opções estratégicas de organização sindical. São Paulo, 1999. 28p. (mimeo).

CHALOULT, Yves; BRUNELLE, Dorval.

Transnacionalização das práticas sindicais: quadro teórico-analítico. Revista Brasileira de Política Internacional, Brasília, v. 41, n. 2, p. 83-101, 1998.

DIEESE. Departamento Intersindical de Estatística e Estudos Sócio-Econômicos. O comportamento das negociações coletivas nos anos 90: 19931996. Pesquisa DIEESE n. 15, São Paulo, maio 1999.

A situação do trabalho no Brasil. São Paulo: DIEESE, 2001a.

Um balanço da participação dos trabalhadores nos lucros e resultados das empresas (1996-1999). São Paulo: DIEESE, $2001 b$.
Negociação coletiva e eqüidade de gênero no Brasil. Pesquisa DIEESE, n. 17, ago. 2003.

Anote - Informativo Eletrônico do

DIEESE, São Paulo, ano 4, n. 37, abril 2003. Anuário do trabalhador 2005.

$\frac{\text { anos). }}{\text {. Balanço das negociações coletivas (vários }}$ DUNLOP, John T. General theory of industrial relations. In: MARSHALL, R; PEARLMAN, R. An anthology of labor economics: readings and commentary. New York: John Wiley and Sons, 1972. p. 547-555.

LARANGEIRA, Sonia M. G. Há lugar para o sindicalismo na sociedade pós-industrial? Aspectos do debate internacional. São Paulo em Perspectiva, São Paulo, v. 12, n. 1, p. 174-183, 1998.

MTE. Ministério do Trabalho e Emprego. Fórum Nacional do Trabalho. Reforma sindical: perguntas e respostas. Brasília: MTE, 2005.

NOGUEIRA, Arnaldo J. F. M. Gestão estratégica das relações do trabalho. In: FLEURY, M. T. F. (Org.). As pessoas na organização. São Paulo: Gente, 2002. p.115-132.

OLIVEIRA, Marco A. Tendências recentes das negociações coletivas no Brasil. In: SANTANA, Marco A.; RAMALHO, José R. (Orgs.). Além da fábrica: trabalhadores, sindicatos e a nova questão social. São Paulo: Boitempo, 2003. p. 271-298.

OIT. Organización Internacional del Trabajo. Memoria del director general - reducir el deficit de trabajo decente: un desafío global. In: CONFERENCIA INTERNACIONAL DEL TRABAJO, 89a., 2001; OFICINA INTERNACIONAL DEL TRABAJO GINEBRA, 1. 2001, Genebra. Reporte do Secretario General.

PRADO, Antonio J. C. Mudanças na negociação sindical nos anos recentes. São Paulo em

Perspectiva. São Paulo: Fundação Seade, v. 12, n. 1, 1998. p. 30-34. 
RODRIGUES, Leôncio M. Destino do

sindicalismo. São Paulo: EDUSP, 1999.

RODRIGUES, Iram J. Um laboratório das relações do trabalho: o ABC paulista nos anos 90. Tempo

Social. Revista de Sociologia da USP, São Paulo, v. 14, n. 1, p. 137-157, maio 2002.

TIBERI, Mario. Velhas e novas características dos processos de internacionalização: o caso da União Européia. In: DIEESE (Org.). Emprego e desenvolvimento tecnológico: processos de integração regional. São Paulo: DIEESE, 1999. p. 101-142.

ZYLBERSTAJN, Helio. Os metalúrgicos do ABC: tentando construir o novo/velho sindicato no Brasil. In: CHAHAD, Paulo Z.; CACCIAMALI, Maria C. (Orgs.). Mercado de trabalho no Brasil. São Paulo: LTr, 2003. 